\title{
Rescue removal of disrupted balloon catheter from right coronary artery and aortic arch
}

\author{
Ratunkowe usunięcie przerwanego cewnika balonowego \\ z prawej tętnicy wieńcowej i łuku aorty
}

\author{
Stanisław Bartuś ${ }^{1}$, Tomasz Kameczura², Michał Chyrchel ${ }^{1}$, Marcin Wizimirski ${ }^{1}$, Dariusz Dudek ${ }^{1}$ \\ $12^{\text {nd }}$ Department of Cardiology, Jagiellonian University Medical College, Krakow, Poland \\ ${ }^{2} 1^{\text {st }}$ Clinic of Cardiology and Interventional Electrocardiology with Hypertension, Jagiellonian University Medical College, Krakow, Poland
}

\begin{abstract}
We present the case of a 70-year-old female patient diagnosed with unstable angina, who was qualified to coronarography in a peripheral interventional cardiology department. Critical stenosis of right posterior descending artery was found. During percutaneous coronary intervention, after-stent balloon catheter interrupted and was left partially in the right coronary artery sticking out of the aortic arch. In a second attempt at removal, using an Amplatz GooseNeck snare, operators managed to take the broken balloon out of the intravascular space.
\end{abstract}

Key words: removal of disrupted balloon catheter, removal of catheter

Kardiol Pol 2013; 71, 7: 772-774

A 70-year-old female patient with arterial hypertension, hypercholesterolaemia, and diabetes mellitus type 2 was admitted to an interventional cardiology department due to increasing episodes of chest pain. Troponin I level on admission was $<0.01 \mathrm{ng} / \mathrm{mL}$ (cutoff level 0.03). In the ECG, sinus rhythm with a heart rate of $80 \mathrm{bpm}$ was noted. Echocardiogram revealed normal contractility of the left ventricle with ejection fraction of $60 \%$. In coronary angiogram done through the right radial artery, a non-significant (30-40\%) stenosis of the left anterior descending artery (LAD) and a 90\% stenosis of the right posterior descending artery (RPD) were found.

The patient was qualified for immediate percutaneous coronary intervention ( $\mathrm{PCl}$ ) of RPD. To do this, the operators used a Sheathless Eaucath 6.5 F guiding catheter, BMW, Whisper MS, and Whisper ES wires and balloon catheters (BC) of sizes $2.0 \times 15 \mathrm{~mm}, 2.5 \times 15 \mathrm{~mm}$, and $3.0 \times 15 \mathrm{~mm}$, respectively - expanded up to 12 atmospheres (atm). After the implantation of a drug-eluting stent (DES) Resolute $3.5 \times 15 \mathrm{~mm}$ (14 atm), the operators decided to implant another DES Resolute Integrity $3.5 \times 38 \mathrm{~mm}(14 \mathrm{~atm})$ to the distal part of the right coronary artery (RCA). During removal of the post-stent $\mathrm{BC}$, there was break in the $\mathrm{BC}$ shaft. The proximal part of the $\mathrm{BC}$ remained in the RCA and caused occlusion of ostial and proximal RCA with TIMI 0 flow. The distal part of the BC on fluoroscopy was seen in the aortic arch. Whisper MS wire was executed to distal portion of RCA and predilatations with BC's size: $1.5 \times 15 \mathrm{~mm}, 2.0 \times 15 \mathrm{~mm}$, $2.5 \times 15 \mathrm{~mm}$ and $3.0 \times 15 \mathrm{~mm}$ were performed (up to $14 \mathrm{~atm})$. All these procedures led to the obtaining of distal TIMI 2 flow.

The operators decided to expel the remaining $B C$ from the RCA. They used an AndraSnare AS (Andramed $\mathrm{GmbH}$, Germany); however, the attempt was unsuccessful. In the middle of the procedure, the patient remained in cardiogenic shock, also a short circulatory arrest was noticed: this responded well to external heart massage and the use of catecholamines. Because of a tendency to bradycardia, an endocavitar electrode was inserted to the right ventricle and rigid stimulation of 100/min was set up. The patient was transferred to the coronary care unit. Also i.v. infusion of integrelin and unfractionated heparin in weight-adjusted doses was implemented. After patient stabilisation, she was transferred to the $2^{\text {nd }}$ Department of Cardiology in Krakow. On admission, the patient was in stable condition, with no 


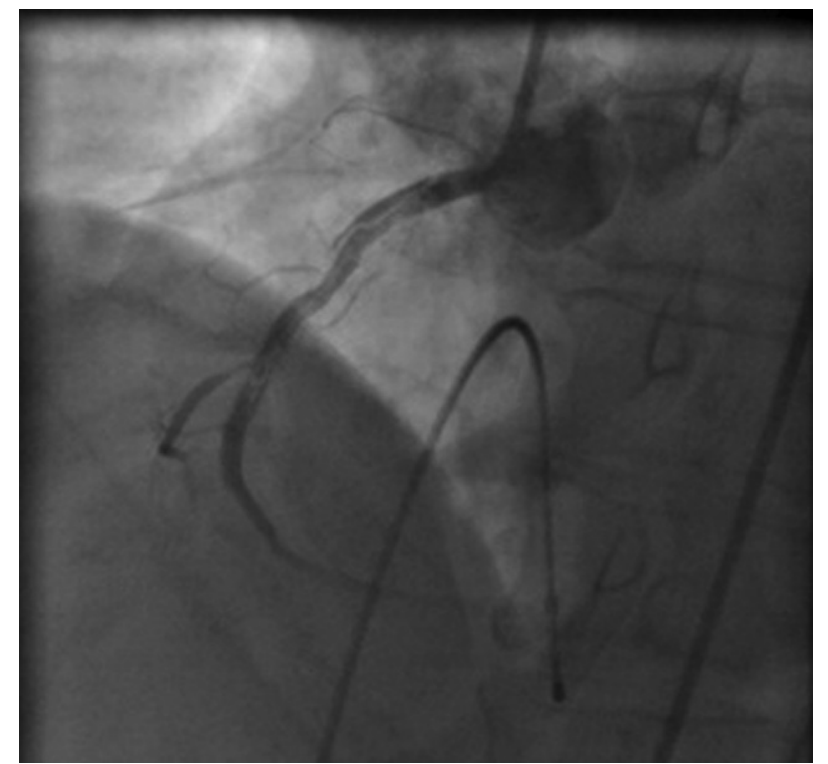

Figure 1. Contrast media injection to right coronary artery — spiral dissection visible in proximal part of the vessel

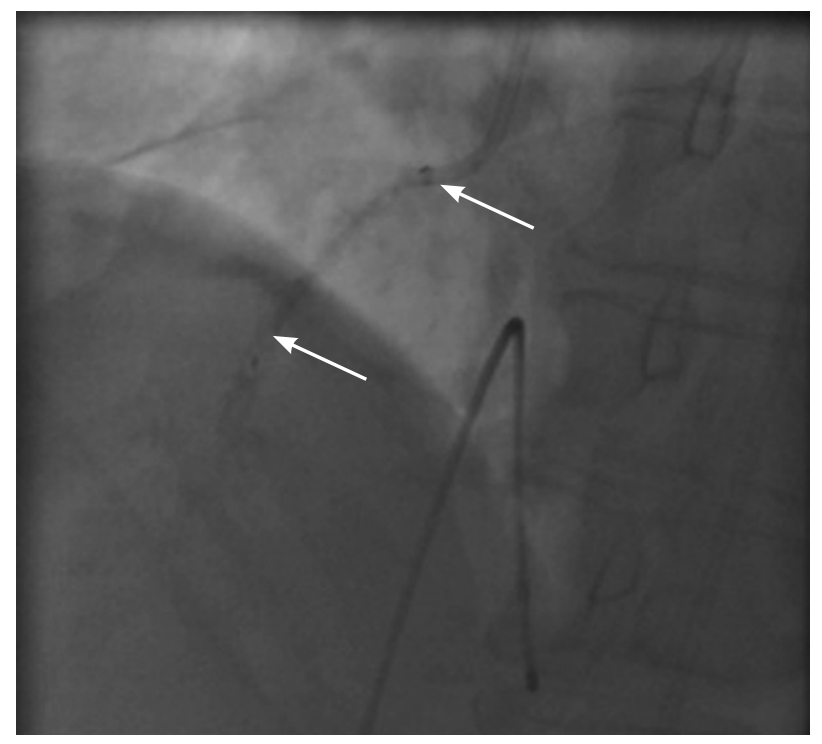

Figure 2. Visible deflated post-stent balloon catheter (marked with arrows)

chest pain. In the control coronary angiogram of the RCA, the spiral dissection was found in the ostium, and I and II segment of artery (Fig. 1). The proximal part of the ruptured BC was also visualised (Fig. 2).

On the day of admission, there was a procedure to remove the broken BC from the RCA. Using the femoral access (7 F) primary to RCA BMW guidewire was inserted. Because of the difficulty of executing the wire through the dissected part of the vessel, the operators replaced it sequentially for guidewires: BHW, Progress 80 and then Floppy II Extra Support.

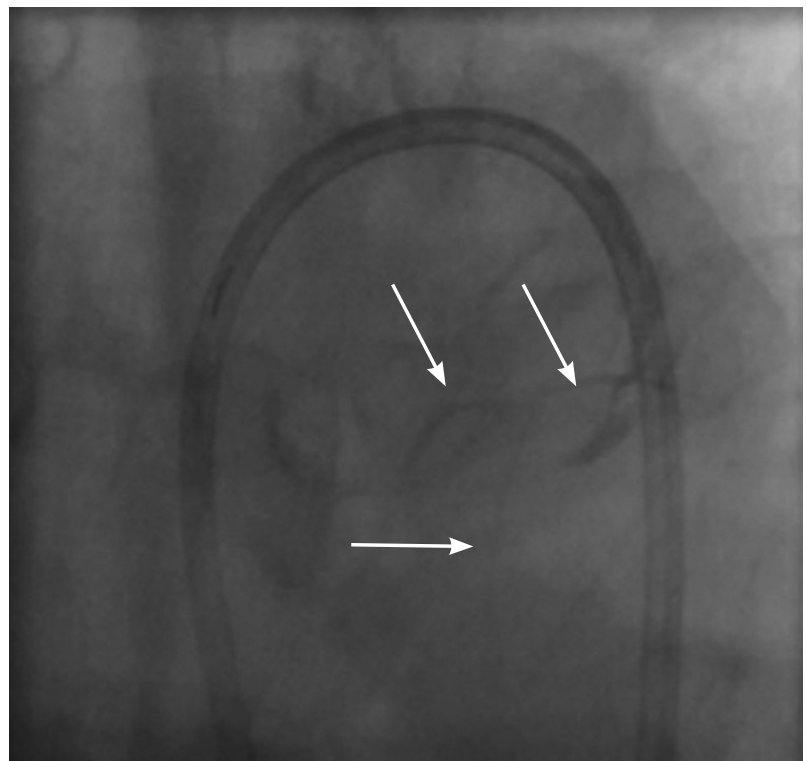

Figure 3. After modification of fluoroscopy projection, distal part of ruptured balloon catheter is visible in the aortic arch (marked with arrows)

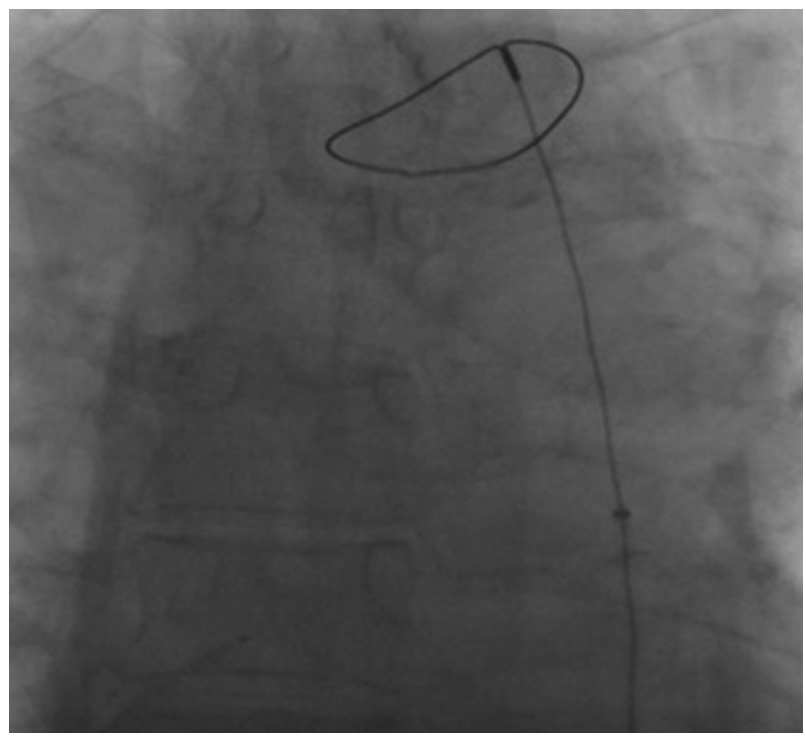

Figure 4. Attempt to catch distal part of broken balloon catheter made with Amplatz GooseNeck ${ }^{\circledR}$

Because of no progress in wires propagation, the decision was made to use an over-the-wire Apex Push microcatheter of $1.5 \times 8 \mathrm{~mm}$. After achievement of distal (non-dissected) part of the RCA in order to achieve left BC system, an Amplatz GooseNeck ${ }^{\circledR}$ was used (maximal loop diameter $2 \mathrm{~mm}$ ). Repeated attempts to catch the proximal part of the $\mathrm{BC}$ had no success.

Unfortunately, the shaft of the broken BC had not been measured before it had been thrown away in the peripheral cathlab, so the operators in the Clinic initially had a problem 


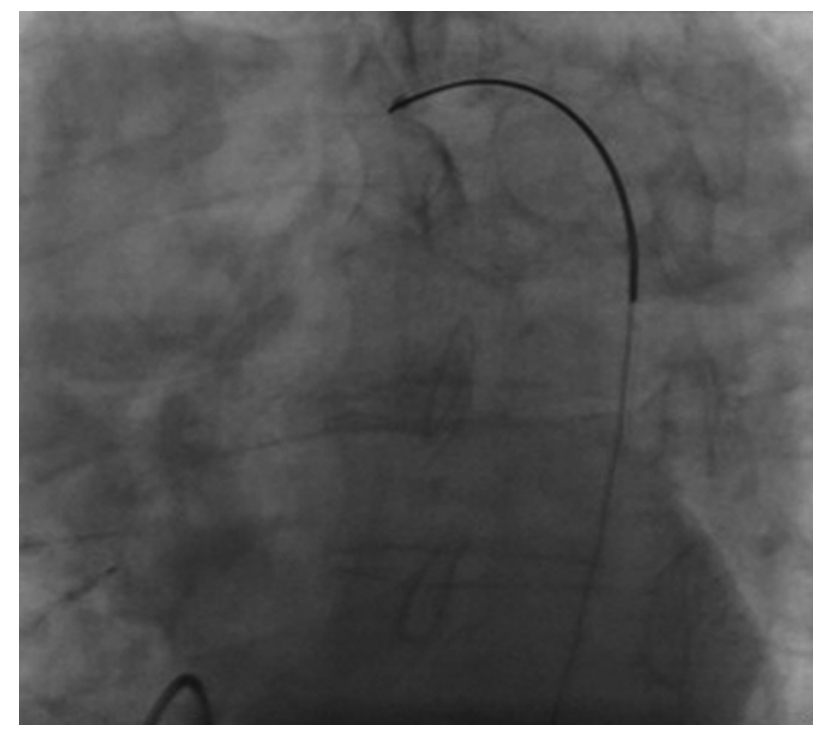

Figure 5. Successful attempt to grip broken balloon catheter. Visible clamped loop

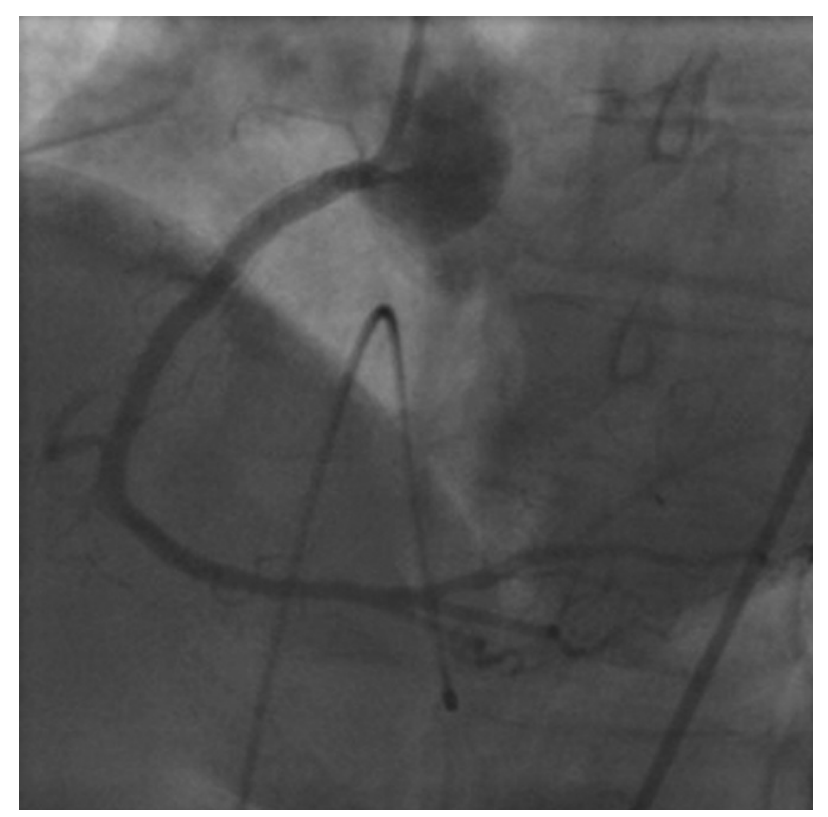

Figure 6 . Final results of percutaneous coronary intervention of proximal segment of right coronary artery with stent implantation

estimating the length of broken BC. By using the fast frame function of fluoroscopy, operators visualised the proximal end of the broken $\mathrm{BC}$ in the area of ostium of the left subclavian artery (Fig. 3). Using the Amplatz GooseNeck ${ }^{\circledR}$ (maximal loop

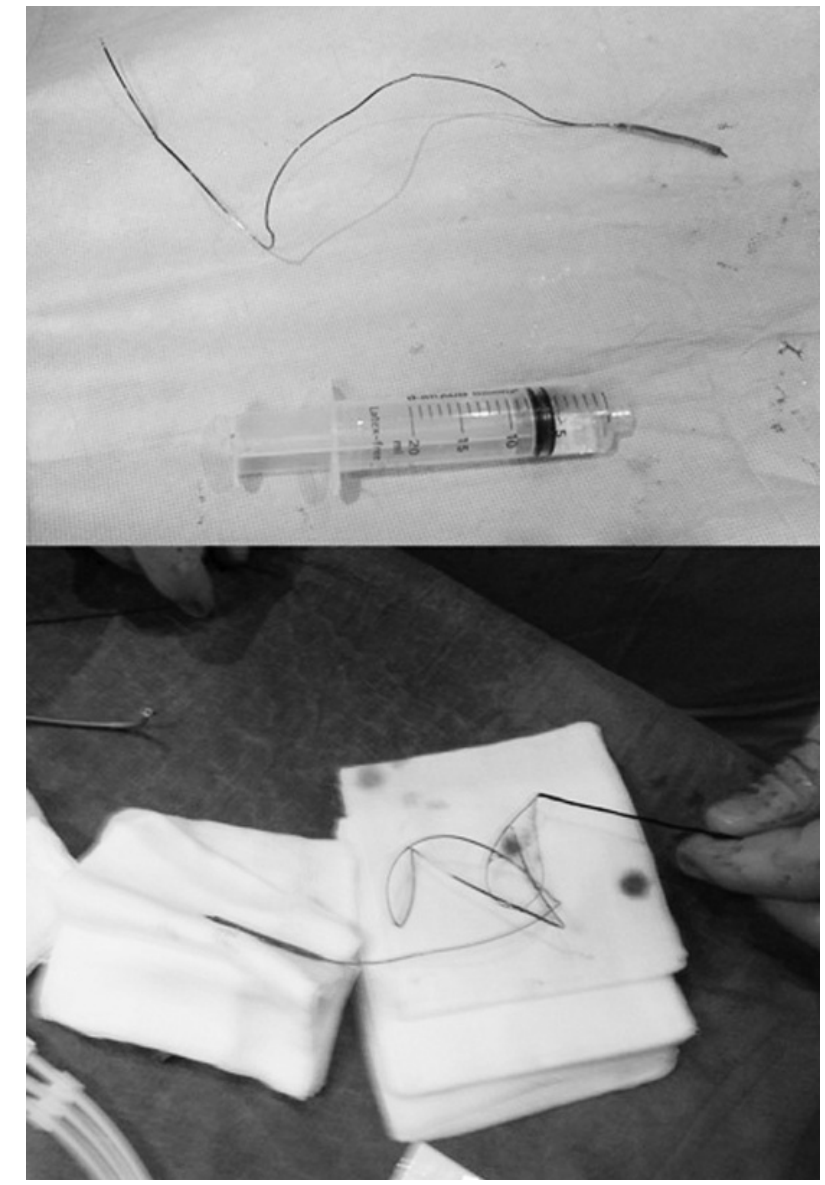

Figure 7. Removed broken balloon catheter from right coronary artery and aortic arch

diameter $20 \mathrm{~mm}$ ), after a few attempts the proximal part of the BC was captured (Figs. 4, 5) and then removed. PCl of RCA with DES Resolute Integrity $3.5 \times 22 \mathrm{~mm}-14 \mathrm{~atm}$ and Resolute Integrity $3.0 \times 16 \mathrm{~mm}-14 \mathrm{~atm}$ (distal RCA) was performed. Additional inflation in ostium up to $22 \mathrm{~atm}$ was also done (Fig. 6). The shaft of the BC after removal was approximately $30 \mathrm{~cm}$ in length and was removed as a whole (Fig. 7). The second procedure lasted $130 \mathrm{~min}$. Radiation dose was $1.14 \mathrm{~Gy}$, and total contrast media volume was $300 \mathrm{~mL}$. The patient was discharged home in good condition after a five-day hospitalisation.

Skill in treating $\mathrm{PCl}$ complications and knowledge of removal equipment capabilities is crucial for minimising the risk of the procedure and the risk of thoracotomy.

Conflict of interest: none declared 